\title{
NON-INTRUSIVE, FAST AND SENSITIVE AMMONIA DETECTION BY LASER PHOTOTHERMAL DEFLECTION
}

\author{
H. S. M. DE VRIES, ${ }^{*}$ F. J. M. HARREN,* G. P. WYERS, $\uparrow$ R. P. OTJES, $†$ \\ J. SLANINA, $\dagger$ and J. REUSS* \\ *Department of Physics, University of Nijmegen, Toernooiveld, 6525 ED Nijmegen, The Netherlands and \\ $\nmid$ Netherlands Energy Research Foundation ECN, P.O. Box 1, 1755 ZG Petten, The Netherlands
}

(First received 1 August 1994 and in final form 23 January 1995)

\begin{abstract}
A recently developed non-intrusive photothermal deflection (PTD) instrument allows sensitive, rapid and quantitative detection of local ammonia concentrations in the air. Ammonia is vibrationally excited by an infrared $\mathrm{CO}_{2}$ laser in an intracavity configuration. A HeNe beam passing over the $\mathrm{CO}_{2}$ laser beam (multipass arrangement) is deflected by the induced refractive index gradient. The detection limit for ammonia in ambient air is $0.5 \mathrm{ppbv}$ with a spatial resolution of a few $\mathrm{mm}^{3}$. The time resolution is $0.1 \mathrm{~s}$ (single line) or $15 \mathrm{~s}$ (multi line). The system is fully automated and suited for non-stop measuring periods of at least one week. Results were compared to those obtained with a continuous-flow denuder (CFD).
\end{abstract}

Key word index: Ammonia, trace gases, photothermal deflection

\section{INTRODUCTION}

Ammonia and ammonium contribute to soil acidification and disturb the nutrient cycle. In The Netherlands dry deposition of ammonia, mainly originating from domestic emission sources (livestock wastes), is responsible for approximately $33 \%$ of the total acidifying deposition (Heij and Schneider, 1991).

Fast and sensitive detection methods for ammonia are needed to quantify air-to-surface exchange fluxes (Erisman et al., 1988). Attempts towards quantitative detection of ammonia employing (isotopic) $\mathrm{CO}_{2}$ laser based photoacoustic spectroscopy and (less sensitive) direct absorption detection systems lately received attention (Olafsson et al., 1989; Meienburg et al., 1990; Rooth et al., 1990; Sauren et al., 1991). Ammonia possesses high absorption coefficients and a clear fingerprint spectrum in the ${ }^{12} \mathrm{CO}_{2}$ and ${ }^{13} \mathrm{CO}_{2}$ laser wavelength regions (Trushin, 1992). The photoacoustic method allows detection of ammonia at sub-ppbv levels. Spectral interference can be minimized either by tuning the laser or by making use of the Stark shift induced in polar gases by an external electric field. A serious drawback of the photoacoustic technique is the necessity to use a flow-through system to lead gases from the sampling zone into the photoacoustic cell. Due to sticking of polar gases to wall material of tubing and photoacoustic cell, unavoidable memory effects of ammonia (large permanent dipole moment) impede fast concentration measurements (Henningsen, 1994).
Another laser based detection system, VUV/ photofragmentation laser-induced fluorescence, is more sensititive (10 pptv for $1 \mathrm{~min}$ integration periods) and free of interferences (Schendel et al., 1990), but also requires a closed cell. The cost of this equipment will probably limit its widespread use. At this moment a Cavity Ring Down technique, which allows to determine $10 \mathrm{ppbv}$ ammonia over a path length of typically $500 \mathrm{~mm}$ with a temporal resolution of $50 \mu \mathrm{s}$, is being developed (Jongma et al., 1995). Its sensitivity can probably be increased by at least one order of magnitude; not, however, its spatial resolution.

A relatively inexpensive, thoroughly tested and reliable detection system for ammonia (sufficiently selective and sensitive: 8 pptv) is the continuous-flow denuder (CFD; Wyers et al., 1993). This instrument is used for routine deployment in the field and micrometeorological measurements of exchange fluxes. However, its response time (1 $\mathrm{min})$ is inadequate for eddy correlation measurements that rely on the covariation of fluctuations in vertical wind speed and concentration to derive ammonia fluxes.

Here, the photothermal deflection (PTD) technique was applied to perform fast and in situ measurements of ammonia concentrations in ambient air. The method is closely related to the photoacoustic technique in which a change in pressure is detected by a microphone (Harren et al., 1990). In PTD, a change in temperature induces a change in refractive index which is being probed by a second laser beam 
(Jackson et al., 1981). Non-intrusive measurements can be performed under normal atmospheric conditions in open air (de Vries et al., 1993).

In this paper the suitability of PTD for ammonia measurements is demonstrated. The characteristics of PTD are compared to results obtained with the continuous flow denuder. Attention was paid to the absolute and relative precision in determining ammonia concentrations, to response time under different conditions and to the effect of interfering gases.

\section{THE PHOTOTHERMAL DEFLECTION SETUP}

The PTD setup consists of a high power waveguide $\mathrm{CO}_{2}$ pump laser and a deflection unit positioned inside the cavity of the $\mathrm{CO}_{2}$ laser (Fig. 1). The $\mathrm{CO}_{2}$ laser emits radiation in the infrared between 9 and $11 \mu \mathrm{m}$ at about 90 different laser lines. Due to a high reflecting output coupling mirror ( $98.5 \%$ reflectivity) the maximum intracavity laser power is $100 \mathrm{~W}$. The curved output mirror and an intracavity $\mathrm{ZnSe}$ lens $(f=75 \mathrm{~mm})$ form a sharp intracavity focus with a (calculated) waist of $0.282 \mathrm{~mm}$ (Harren et al., 1990). The infrared $\mathrm{CO}_{2}$ laser radiation promotes ammonia into a ro-vibrational level of the $v_{2}$ mode. The strong difference in absorption strength of ammonia at the neighbouring $10 \mathrm{R} 8$ and the $10 \mathrm{R} 10 \mathrm{CO}_{2}$ laser lines $\left(20.5 \mathrm{~atm}^{-1} \mathrm{~cm}^{-1}\right.$ at $\lambda=10.334 \mu \mathrm{m}$ and $0.542 \mathrm{~atm}^{-1}$ $\mathrm{cm}^{-1}$ at $\lambda=10.318 \mu \mathrm{m}$, respectively; Brewer and Bruce, 1978) allow one to determine the ammonia concentration corrected for any background absorption.

Due to non-radiative collisional decay the laser interaction zone and the immediate surrounding region are heated, causing a change of refractive index. A probe $\mathrm{HeNe}$ laser beam $(632.8 \mathrm{~nm})$ passes (perpendicularly to the pump beam) close to this heated zone; its deflection, due to the refractive index gradient induced by the $\mathrm{CO}_{2}$ laser, is proportional to the concentration of the absorbing gas and the available $\mathrm{CO}_{2}$ laser power. The sensitivity of the system is enhanced by using a parallel-mirror multipass arrangement for the probe beam; it traverses the heated region 31 times (de Vries et al., 1992). The spatial resolution of the PTD instrument is defined by the waist of the $\mathrm{CO}_{2}$ laser and the spatial overlap of $\mathrm{CO}_{2}$ - and $\mathrm{HeNe}$-laser beam and has the shape of a cylinder with a diameter of $0.56 \mathrm{~mm}$ and a length of $25 \mathrm{~mm}$. The interaction length can be reduced (from 25 to $2 \mathrm{~mm}$ ) using cylindrical lenses and mirrors instead of flat mirrors for the multipass probe laser setup, however, in this setup the overall sensitivity of the system is reduced (de Vries et al., 1995).

The pump laser is periodically interrupted by a mechanical chopper $(20 \mathrm{~Hz}$ or $60 \mathrm{~Hz}$; home built), giving rise to a modulated deflection of the probe beam. The deflection is phase sensitively measured by a position sensing quadrant detector (Centronic, QD 50-2), the output of which is fed into a lock-in amplifier (PAR 5204). The whole setup is computer controlled and capable of unattended long term operation.

The probe $\mathrm{HeNe}$ laser beam with the multipass system and the position sensitive detector are all stably mounted in a frame constituting the deflection unit. The frame of the pump $\mathrm{CO}_{2}$ laser and the deflection unit are rigidly coupled to avoid mechanical vibrations between the two laser beams.

The effect of air turbulences is minimized by shielding the entire frame (except for the detection region) and by utilizing a double probe beam arrangement. In this double probe beam setup one HeNe laser beam is affected by the induced refractive index gradient (crossing about $1 \mathrm{~mm}$ from the $\mathrm{CO}_{2}$ laser waist) and the other not (crossing $7 \mathrm{~mm}$ below). Upon subtracting both signals the influence of air turbulence is reduced by a factor of two (de Vries $e t$ al., 1993). All measurements presented in this paper were performed with the double probe beam arrangement.

For operation at one single $\mathrm{CO}_{2}$ laser line the temporal resolution is determined by the RC-time of the lock-in amplifier $(0.1 \mathrm{~s})$. To detect very low concentrations of ammonia one must take into account changes in concentrations of other (interfering) gases noted as background signals. Therefore, switching between two neighbouring $\mathrm{CO}_{2}$ laser lines, one strongly and one weakly absorbing line will spectroscopically purify the ammonia signal. In our current setup the switching time between the two laser lines, including piezo optimization, was $15 \mathrm{~s}$.

\section{Interfering gases}

In the wavelength region of the $\mathrm{CO}_{2}$ laser the most important gases spectroscopically interfering with ammonia are $\mathrm{CO}_{2}$ and $\mathrm{H}_{2} \mathrm{O}$ with ambient concentrations in the order of $360 \mathrm{ppmv}$ and $0.5-1.5 \%$, respectively. The interfering absorption spectrum of atmospheric $\mathrm{CO}_{2}$ is the inverse vibrational hot band transition from which $\mathrm{CO}_{2}$ laser radiation is generated, resulting in a background signal equivalent to $34 \mathrm{ppbv} \mathrm{NH}_{3}$ at the 10R8 (Devir and Oppenheim, 1969). At $294 \mathrm{~K}$ the background signal due to atmospheric water vapour concentration is two orders of magnitude lower ( < $0.6 \mathrm{ppbv} \mathrm{NH}_{3}$, Loper et al., 1983). Fortunately, absorption coefficients for $\mathrm{CO}_{2}$ and $\mathrm{H}_{2} \mathrm{O}$ at 10R8 and $10 \mathrm{R} 10$ are comparable so that variations in concentration of these gases will contribute equally to the deflection signals on both lines. Only the difference in absorption strength will affect the real ammonia concentration (maximum 4.6 and $0.1 \mathrm{ppbv}$ for $360 \mathrm{ppmv} \quad \mathrm{CO}_{2}$ and $1.5 \%$ water vapor, respectively). Since water, like ammonia, has a dipole moment strong memory effects can appear in flow through systems; due to the intrinsic contact-free PTD method this problem is avoided and precise 

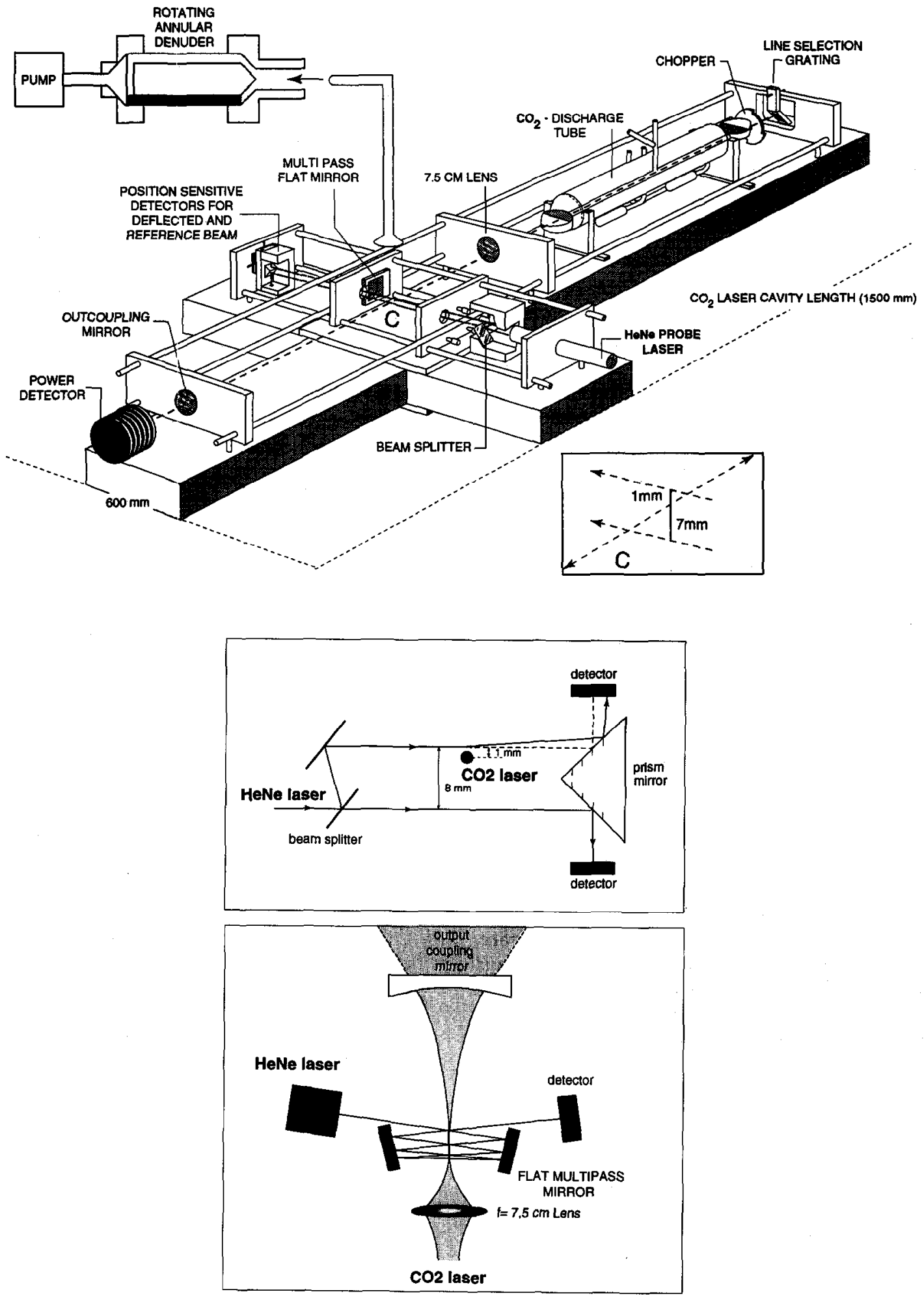

Fig. 1. The rigid body frame for PTD consists of an intracavity $\mathrm{CO}_{2}$ laser setup (including line selecting grating, chopper, convergent lens $(f=75 \mathrm{~mm}$ ) and output coupling mirror) and dual HeNe probe laser beams. The dual beams are obtained by a beam splitter unit (dimensions are indicated). The air is sampled above the multipass area by the rotating annular denuder unit. The interaction region of probe beam and $\mathrm{CO}_{2}$ laser beam is presented in detail. The probe beam influenced by the mirage effect traverses the $\mathrm{CO}_{2}$ laser beam at a distance of $1 \mathrm{~mm}$; the reference beam at a distance of $7 \mathrm{~mm}$ under the $\mathrm{CO}_{2}$ laser beam (upper part). In the interaction region a multipass configuration is implemented (lower part). 
measurements of water concentrations are possible. A good coincidence exists between a single rotational transition of water $\left(J\left(K_{-1}, K_{1}\right)=13(4,9) \leftarrow 12(1,12)\right.$; Hinderling et al., 1985) and the $10 \mathrm{R} 20 \mathrm{CO}_{2}$ laser line; at the $10 \mathrm{R} 20$ the absorption is approximately 20 times higher than that at the 10R18 laser line. As mentioned above ${ }^{12} \mathrm{CO}_{2}$ has a broad absorption spectrum on ${ }^{12} \mathrm{CO}_{2}$ laser lines; on ${ }^{13} \mathrm{CO}_{2}$ laser lines (Trushin, 1992) it has a clear fingerprint spectrum.

\section{Calibration}

The system was calibrated using a certified mixture of 1.2 ppmv ethylene in purified nitrogen. Ethylene is a well known calibration gas without any wall adsorption problems. Additional calibration was made for $1.2 \mathrm{ppmv}$ (certified) and ambient (about 4 ppbv) ethylene levels with a flow-through system employing photoacoustic spectroscopy (Harren et al., 1990) and by comparing PTD detection on gaseous ammonia levels in open air with the values obtained by a continuous-flow denuder system.

\section{CONTINUOUS-FLOW DENUDER}

In order to compare (estimated) ammonia concentrations in the PTD detection zone with values obtained with a continuous-flow denuder (CFD), a polyethylene tube, to sample air, was positioned above this zone.

The CFD is a wet-chemical detector specific to ammonia. Air is pumped through the CFD at a rate of $30 \ell \mathrm{min}^{-1}$. The ammonia present in the air is absorbed in a $\mathrm{NaHSO}_{4}$ solution, covering the denuder inner wall. Further downstream this solution is mixed with $\mathrm{NaOH}$, resulting again in gaseous ammonia, that diffuses through a semi-permeable membrane. On the other side of the membrane, ammonia is dissolved in bi-demineralized water and the concentration determined conductometrically. This system was calibrated using a blank, a 50 ppbv and a 500 ppbv aqueous solution of $\mathrm{NH}_{4}^{+}$(Wyers $e t$ al., 1993).

\section{APPLICATION TO VARYING AMMONIA CONCENTRATIONS}

\section{Comparison of absolute values}

Ambient ammonia concentration levels were determined independently with PTD and CFD systems in a laboratory during periods of one week (non-stop). During the night ammonia concentrations were on average 3 ppbv lower than daytime levels (that fluctuated slowly between 10 and $20 \mathrm{ppbv}$ ). The denuder tubing was positioned $0.1 \mathrm{~m}$ above the PTD sampling zone. Solutions of $0.25-2.5 \%$ of ammonia in demineralized water were prepared and localized at a distance of $0.5 \mathrm{~m}$ from denuder tube and PTD detection zone, resulting in concentrations of about $10,30,60$ and $120 \mathrm{ppbv}$ in the sampling zone. The correlation of CFD and PTD signals yielded a straight line (Fig. 2; slope of 1.02(5)). For CFD the calibration is based on reference solutions, while PTD calibration relies on $\mathrm{C}_{2} \mathrm{H}_{4}$ measurements. Absorption strengths $\left(20.5 \mathrm{~atm}^{-1} \mathrm{~cm}^{-1}\right.$ for $\mathrm{NH}_{3}$ on the $10 \mathrm{R} 8$ and $13.4 \mathrm{~atm}^{-1} \mathrm{~cm}^{-1}$ for $\mathrm{C}_{2} \mathrm{H}_{4}$ on the 10P14) and the laser power were taken into account. The absorption coefficient for $\mathrm{C}_{2} \mathrm{H}_{4}$ on the 10P14 is lower than mentioned in literature $\left(30.4 \mathrm{~atm}^{-1} \mathrm{~cm}^{-1}\right.$, Brewer et al., 1978) due to saturation effects.

Different ammonia concentrations, measured by PTD and CFD, observed as a function of time are shown in Fig. 3. Ambient ammonia levels at $t=0$ are displayed. Following $t=0.2 \mathrm{~h}$ the ammonia level is seen to rise, due to a source ( $2.5 \%$ aqueous ammonia) placed $0.5 \mathrm{~m}$ from the detection area. At $t=0.52 \mathrm{~h}$ the ammonia source was removed which resulted in ambient levels again. Short term variations in ammonia

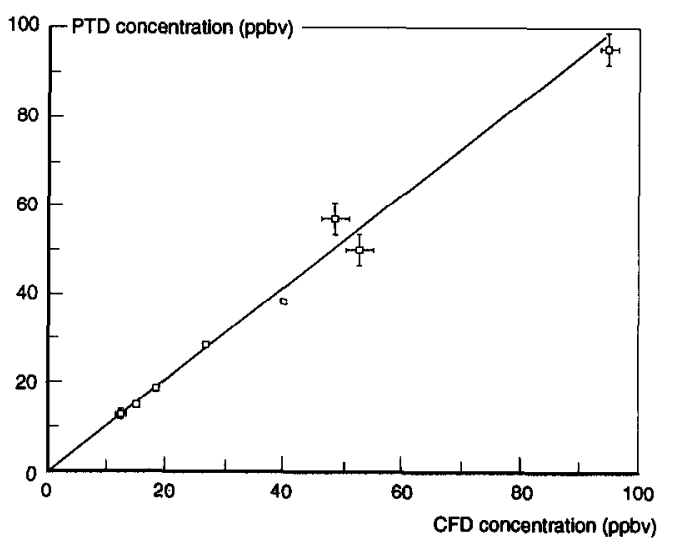

Fig. 2. Correlation of ammonia concentrations obtained with CFD and PTD.

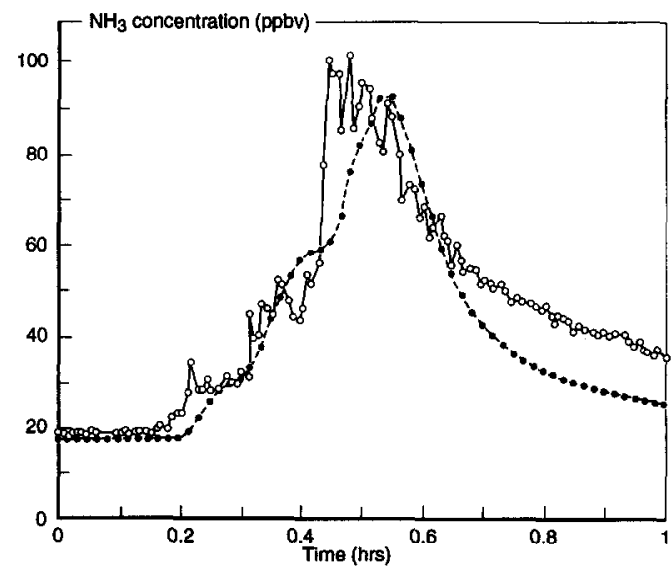

Fig. 3. Ammonia concentrations in detection zone measured by PTD (-o-) and just above detection zone by CFD (-๑). Initial, ambient levels were observed. Then, after $0.2 \mathrm{~h}$, an ammonia solution was positioned about $50 \mathrm{~cm}$ from the detection zone and an increase in ammonia amounting to $100 \mathrm{ppbv}$ observed. At $t=0.52 \mathrm{~h}$ the solution was removed leading to ambient levels again. 
concentration of $10 \mathrm{ppbv}$ (on an average concentration of $100 \mathrm{ppbv}$ ) were observed only by PTD. Because of its integrating character such rapid changes of ammonia concentrations cannot be observed by CFD. The noise on the PTD signal (equivalent to 0.5 ppbv $\mathrm{NH}_{3}$ at $t=0$, Fig. 3) is much less than the fluctuations observed on the peak signal $(10 \mathrm{ppbv}$ at $t=0.5 \mathrm{~h}$ ). These increased fluctuations are due to occurrence of air turbulences in the source/sample region, to relatively small dimensions of the ammonia source (when compared to the sampling volume) and to high CFD suction rates. The relatively small ammonia source did not yield a steady ammonia concentration in the sampling zone. High suction rates perturb local concentrations even more, causing rapid concentration changes in the surroundings of the denuder tubing, whereas ammonia concentrations in the PTD zone change merely through diffusion. This also explains the steeper tail of the CFD curve. Consequently, comparison of absolute ammonia concentrations by PTD and CFD systems in an open air environment is allowed only for large sampling volumes under steady ammonia conditions.

\section{Fast ammonia fluctuations}

A double flow system, utilizing either normal air (containing ambient: ammonia concentrations) or air containing above-ambient ammonia levels, was used for rapid switching (seconds) between different ammonia concentrations. The flowing gas was led directly into the detection zone (flow rate $15 \ell \mathrm{h}^{-1}$ ), through a tubing positioned $20 \mathrm{~mm}$ below the intersection region of pump and probe laser beams. The denuder tubing was installed $20 \mathrm{~mm}$ above the multipass system. Such short distances allowed investigation of rapidly changing ammonia concentrations reaching quasi-simultaneously both detection systems; results are presented in Fig 4. The arrows indicate time instants at which higher ammonia levels were purged into the detection region, during 1,2 or $3 \mathrm{~s}$. The CFD technique displays a smeared-out effect (dashed curve), whereas the PTD setup (single line operation on the ammonia absorbing laser line (10R8)) detects ammonia passing in pulses through the detection zone.

The signal on the less strongly absorbing $10 \mathrm{R} 10$ laser line (lower trace in Fig. 4) remains constant. An important conclusion is that the signal is affected neither by air turbulences nor by varying water concentrations. However, with the actual PTD system it was not possible to carry out simultaneous measurements on the 10R8 and 10R10 $\mathrm{CO}_{2}$ laser lines faster than $15 \mathrm{~s}$. Therefore, the measurements of Fig. 4 were performed directly after each other. Note that the ammonia concentration can be calculated by subtracting signals on the $10 \mathrm{R} 8$ and 10R10, taking into account absorption coefficients and intracavity laser power on these lines, as it is done for the results in Figs 2 and 3. The figures suggest no influence of water vapour.

The shape of the ammonia concentration profile, determined by PTD (10R8), depends on the relative position of the tube openings of the double flow system with respect to the detection zone. Results acquired at another position of the tube opening are shown in the insert of Fig. 4.

\section{CONCLUSIONS}

Table 1 summarizes sensitivity, data on temporal resolution and important experimental features in measuring ammonia for both PTD and CFD. One major conclusion is that the PTD setup enables

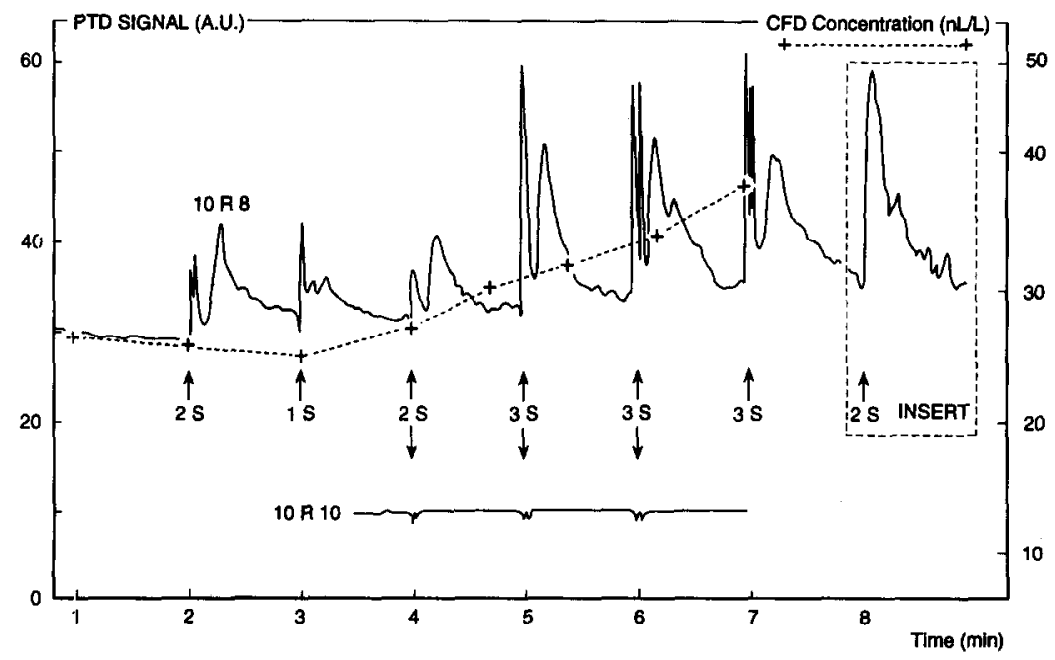

Fig. 4. Fast ammonia changes produced by flushing ammonia enriched air through detection area for 1,2 or $3 \mathrm{~s}$. The CFD displays a slowly increasing curve (dashed), while PTD registers rapid changes on the 10R8 ammonia absorbing laser line and no change on 10R10 non-absorbing laser line. A PTD curve is inserted on the right showing that the profile is dependent on a position of the tube above the detection zone. 
Table 1. Comparison between the PTD setup and the CFD for ammonia measurements; the sensitivity for the two laser line measurements is given in Fig. 3

\begin{tabular}{|c|c|c|}
\hline & PTD & CFD \\
\hline Sensitivity & $0.5 \mathrm{ppbv}$ (RC-time $1 \mathrm{~s}, 20 \mathrm{~Hz}$ ) & 8 pptv (RC-time $60 \mathrm{~s}$ ) \\
\hline Time response & $\begin{array}{l}15 \mathrm{~s} \text { (two laser lines) } \\
0.1 \mathrm{~s} \text { (one laser line, RC-time } 0.1 \mathrm{~s}, 60 \mathrm{~Hz} \text { ) }\end{array}$ & $1 \mathrm{~min}$ \\
\hline Condition & $\begin{array}{l}\text { Non-intrusive local detection } \\
\text { Detection zone } 25 \mathrm{~mm} \times \pi(0.282 \mathrm{~mm})^{2}\end{array}$ & Suction gas sampling \\
\hline
\end{tabular}

measurements of absolute ammonia concentrations with a detection limit of $0.5 \mathrm{ppbv}$ (signal-to-noise ratio $=1$ ). The range of $10-120$ ppbv is covered experimentally. Within this range the photothermal response is linear with the applied concentrations (verified by CFD) under steady ambient conditions. At low concentrations the PTD signal is reproducible within the detection limit; at high concentrations ( $\mathbf{S} / \mathrm{N}$ larger than 1000) the error is determined by detector noise.

Another major conclusion is that the time responses of PTD (15 s on double line operation, $0.1 \mathrm{~s}$ on single line operation) are significantly faster than that of CFD, allowing observations of rapid changes in ammonia concentrations. Neither changes in water vapour nor $\mathrm{CO}_{2}$ concentrations perturb ammonia measurements. By using other $\mathrm{CO}_{2}$ laser lines the setup is also suitable for calibrated water vapour measurements.

The advantage of PTD over currently existing techniques is the possibility to determine local ammonia concentrations in an open air environment, without perturbation of the environment and without wall adsorption problems, which makes it suitable for eddy correlation measurements. Further objectives will be detection of reactive (ozone) or adsorbing gases (e.g. water and ammonia); from which ammonia measurements will be performed in relation to nitrogen fixation problems (reduction of $\mathrm{N}_{2}$ to ammonia in cyanobacteria).

Acknowledgements - Wc would like to thank N. Dam for comments and suggestions on this paper, and $M$. van Lieshout for experimental support and an unknown referee for thoroughly reviewing this manuscript.

\section{REFERENCES}

Brewer R. J. and Bruce C. W. (1978) Photoacoustic spectroscopy of $\mathrm{NH}_{3}$ at the $9-\mu \mathrm{m}$ and $10-\mu \mathrm{m}{ }^{12} \mathrm{C}^{16} \mathrm{O}_{2}$ laser. $A p p l$ Opt. 17, 3746-3749.

Devir A. D. and Oppenheim U. P. (1969) Line width determination in the 9.4 $\mu \mathrm{m}$ and $10.4-\mu \mathrm{m}$ bands of $\mathrm{CO}_{2}$ using a $\mathrm{CO}_{2}$ laser. Appl. Opt. 8, 2121-2123.

de Vries H. S. M., Dam N., van Lieshout M. R., Sikkens C., Harren F. J. M. and Reuss J. (1995) An on line, nonintrusive trace gas detector based on laser photothermal deflection. Submitted.

de Vries H. S. M., Harren F. J. M. and Reuss J. (1992) The photothermal deflection technique (PDT); Fast trace gas detection in the atmosphere. In Springer Series in Optical Science, Vol. 69 (edited by Bicanic D. D.), pp. 12-15. Springer, Heidelberg.

de Vries H. S. M., Harren F. J. M., van Opbergen M. P. A. and Reuss J. (1993) In situ detection of ethylene and ammonia using the photothermal deflection technique. Air pollution research report 47, ISBN, 2-87263-095-3.

Erisman J. W., Vermetten A. W. M., Asman W. A. H., Waijers-IJpelaan A. and Slanina J. (1988) Vertical distribution of gases and aerosols: the behaviour of ammonia and related components in the lower atmosphere. Atmospheric Environment 22, 1153-1160.

Harren F. J. M., Bijnen F. G. C., Reuss J., Voesenek L. A. C. J. and Blom C. W. P. M. (1990) Sensitive intracavity photoacoustic measurements with a $\mathrm{CO}_{2}$ waveguide laser. Appl. Phys. B 50, 137-144.

Heij G. J. and Schneider T. (1991) Acidification Research in the Netherlands. Studies in Environmental Science. Elsevicr, Amstcrdam.

Henningsen J. (1994) Personal Communication.

Hinderling J., Sigrist M. W. and Kneubuhl F. K. (1985) Pure rotational transitions of $\mathrm{H}_{2} \mathrm{O}$ molecules in the 8-14 $\mu \mathrm{m}$ atmospheric window. Infrared Phys. 25(1/2), 491-496.

Jackson W. B., Amer N. M., Boccara A. C. and Fournier D. (1981) Photothermal deflection spectroscopy and detection. Appl. Opt. 20, 1333-1344.

Jongma R. T., Boogaarts M. G. H., Holleman I. and Meijer G. (1995) Trace gas detection with cavity ring down Spectroscopy. Rev. Sci. Instrum. 66(4), in press.

Loper G. L., O'Neal M. A. and Gelbwachs J. A. (1983) Water-vapor continuum $\mathrm{CO}_{2}$ laser absorption spectra between $27^{\circ} \mathrm{C}$ and $10^{\circ} \mathrm{C}$. Appl. Opt. 22, 3701-3710.

Meienburg W., Neckel H. and Wolfrum J. (1990) In situ measurement of ammonia with a ${ }^{13} \mathrm{CO}_{2}$-waveguide laser system. Appl. Phys. B 51, 94-98.

Olafsson A., Hammerich M., Bülow J. and Henningsen J. (1989) Photoacoustic detection of $\mathrm{NH}_{3}$ in power plant emission with a $\mathrm{CO}_{2}$ laser. Appl. Phys. B 49, 91-97.

Rooth R. A., Verhage A. J. L. and Wouters L. W. (1990) Photoacoustic measurement of ammonia in the atmosphere: influence of water vapor and carbon dioxide. Appl. Opt. 29, 3643-3653.

Sauren J. J. A. M., Bicanic D. and van Asselt K. (1991) Photoacoustic detection of ammonia at the sum and difference sidebands of the modulating laser and stark electric fields. Infrared Phys. 31, 475-484.

Schendel J. S., Stickel R. E., van Dijk C. A., Sandholm S. T., Davis D. D. and Bradshaw J. D. (1990) Atmospheric ammonia measurement using a VUV/Photofragmentation laser-induced fluorescence technique. Appl. Opt. 29, 4924-4937.

Trushin S. A. (1992) Photoacoustic air pollution monitoring with an isotopic $\mathrm{CO}_{2}$ laser. Ber. Bunsenges. Phys. Chem. 96, 319-322.

Wyers G. P., Otjes R. P. and Slanina J. (1993) A continuous-flow denuder for the measurement of ambient concentrations and surface-exchange fluxes of ammonia. Atmospheric Environment 27(A), 2085-2090. 